\title{
A REPRESENTAÇÃO DOS PORTADORES DE NECESSIDADES ESPECIAIS NOS LIVROS DIDÁTICOS DE LEM
}

Juliana da Silva PASSOS - UFPR

\begin{abstract}
RESUMO: Este trabalho discute a tendência contemporânea de representar o portador de necessidades especiais nos livros didáticos de língua estrangeira a partir da série Teens Club, material destinado ao ensino de língua inglesa para adolescentes. Tais representações limitam-se a grupos específicos - em geral os cadeirantes - e são, via de regra,estabelecidas através da linguagem visual. Interessa-nos discutir quem é o sujeito representado e o tipo de discurso visual se constrói. Igualmente, interessa-nos o fato destas representações não se construírem no plano da linguagem verbal e como contribuem para a formação da identidade e do discurso social em torno da deficiência.
\end{abstract}

PALAVRAS CHAVE: representação; necessidades especiais; material didático.

\begin{abstract}
This paper discusses the contemporary tendency to represent people with special needs in the textbooks of foreign language, specially based on Teens Club - materials for teaching English language for teens. Such representations are limited and restricted to specific groups - in general the wheelchair user - and are usually established through visual language only. The focus of this paper is the discussion about who the represented subject is and what kind of visual discourse is constructed and for what purposes. The discussion also extends to the fact that these representations are not built in terms of verbal language. It examines as well how they contribute to the identity formation and social discourse of disability.
\end{abstract}

KEYWORDS: representation; disabilities; textbooks.

Este artigo tem como objetivo investigar de que modo se constrói a representação pictórica e discursiva dos portadores de necessidades especiais em livros didáticos de língua estrangeira moderna, tomando como objeto de investigação a série de livros-texto Teens Club, destinada ao ensino de língua inglesa para um público na faixa etária de 11 a 13 anos de idade. Propostas de representação de minorias são uma tendência cada vez mais relevante nos mais diversos contextos e das quais os Estudos Culturais têm com freqüência se ocupado, investigando e julgando de que maneira se dão tais representações. Este trabalho se constrói a partir da perspectiva dos Estudos Culturais em Educação, em especial à luz das pesquisas de Stuart Hall, Tomaz Tadeu da Silva e Kathryn Woodward. Como um campo de estudos consideravelmente 
democrático e abrangente tanto em seus objetos quanto em seus recortes teóricos, é difícil definir objetivamente o que sejam os Estudos Culturais, mas Culler traça o que seria, em linhas gerais, o projeto desta perspectiva:

Em sua concepção mais ampla, o projeto dos estudos culturais é compreender o funcionamento da cultura, particularmente no mundo moderno: como as produções culturais operam e como as identidades culturais são construídas e organizadas, para indivíduos e grupos, num mundo de comunidades diversas e misturadas, de poder do Estado, indústrias da mídia e corporações multinacionais (CULLER, 1999, p. 49).

Em outras palavras, compreender como se constroem as identidades culturais dentro dos mais diversos contextos sociais é de fundamental importância para desnaturalizar e entender tais identidades exatamente como aquilo que são: construções discursivas.

O discurso cultural predomina largamente sobre as teorias baseadas no determinismo biológico, pois por mais que existam é necessidades entendidas como inerentes a todo e qualquer ser humano, independentemente da cultura, existem também divergências em relação ao que seja uma necessidade fundamental, e o que seja supérfluo. A alimentação, o sono e a reprodução, por exemplo, são algumas destas necessidades definidas biologicamente, mas como tais necessidades se realizarão dentro de cada sociedade é extremamente variável, e isto é parte da nossa identidade (PASSOS, 2008, p. 35).

De maneira geral, a identidade é constituída por fatores simples, como a maneira como dormimos ou nos alimentamos, até complexas relações de como nos percebemos no mundo e como percebemos nossos semelhantes. Algumas coisas nos são legadas e outras construídas ao longo de nossa existência nos diferentes sistemas culturais pelos quais somos interpelados. Família, escola e mídia são apenas alguns destes sistemas culturais que podem determinar aquilo que somos por meio da identificação ou não identificação de suas representações.

Tal identificação é uma das principais relações estabelecidas dentro destes sistemas culturais e é determinante na constuição destas identidades e das relações com o outro. Um exemplo claro deste processo pode ser percebido pela recepção das representações veiculadas, sobretudo, pela mídia televisiva. A televisão apresenta os mais variados padrões estéticos e de comportamento: comportamento sexual, moda, linguagem, padrões de beleza, etc. Tais posturas se popularizam ou não por meio de processos de identificação: diferentes comportamentos são 
enaltecidos ou inferiorizados e, de acordo com a relação que estabelecemos com o veículo de comunicação em questão, incorporamos ou não determinados padrões (PASSOS, 2008: 36). Tais representações não passam de criações discursivas que podem passar a ter um status de verdade por meio de um processo de legitimação social e naturalização, que poderá mascarar o fato de que representações são apenas uma possibilidade de discurso. Em relação a essas questões, Said (2007, p. 91-91) ressalta que

\begin{abstract}
Isso é bastante evidente no caso da moda. Por que perucas, golas de renda e sapatos altos afivelados aparecem e desaparecem, num período de décadas? Parte da resposta tem a ver com a utilidade e parte com a beleza inerente da moda. Mas se concordamos que todas as coisas na história, bem como a própria história, são criadas pelos homens, veremos como é grande a possibilidade de que a muitos objetos, lugares ou tempos sejam atribuídos papéis e significados que adquirem validade objetiva só depois de essas atribuições terem sido feitas. Isso vale sobretudo para coisas relativamente incomuns, como estrangeiros, mutantes ou comportamento "anormal" (SAID, 2007, p. 90-91).
\end{abstract}

Assim, as mais diversas representações que nos interpelam através dos diferentes sistemas culturais "povoam o imaginário e, de maneira implícita, estabelecem-se com força nas crenças de verdade das sociedades" (PASSOS, 2009, p. 54). Interessa aos Estudos Culturais a investigação sobre como tais discursos referentes à representação fabricam discursivamente os sujeitos e, ao mesmo tempo, como estas construções constituem os sujeitos modernos e determinam suas relações. Como exemplo disto podemos observar a tese de doutoramento de Kindel (2003), ao dizer que "a natureza no desenho animado ensinando sobre homem, mulher, raça, etnia e outras coisas mais”. Sobre Kindel, comentam Wortman e Veiga-Neto (2001, p. 104-105)

\footnotetext{
Essa autora tem lidado com efeitos constitutivos que as representações contidas nesses desenhos animados têm sobre as crianças, posto que: a bruxa do filme A pequena sereia é gorda; o rei "mau" do filme $O$ Rei Leão é mais escuro que o "bom"; e a personagem Pocahontas, do filme de mesmo nome, é magra, branca e graciosa. Como a autora ressalta, muitos personagens carregam de forma negativa uma representação da diferença, seja ela de gênero, de raça ou de etnia. (WORTMAN \& VEIGA-NETO, 2001, p. 104-105)
}

Representações, como as acima mencionadas, incluem práticas e sistemas simbólicos pelos quais os significados são produzidos, posicionando os seres como sujeito. É por meio destes significados contidos nas representações que atribuímos sentidos às experiências e ao que somos. Em grande parte, esses sistemas simbólicos tornam possível o que somos e aquilo que 
podemos nos tornar. Assim, entendida como um processo cultural, a representação estabelece identidades coletivas e individuais. Os discursos e os sistemas de representação determinam os lugares a partir dos quais os indivíduos se posicionam e a partir de onde falam (WOODWARD, 2000, p. 17). Por isso, a importância da representação dos vários grupos sociais na mídia, na publicidade e nos livros didáticos é fundamental para a constituição da identidade do aprendiz. Com isso, acreditamos que as pessoas pertencentes aos diversos grupos sociais, sendo representados nas mais inúmeras posições, possam se identificar no sentido de não ter suas identidades suprimidas ou inferiorizadas por um discurso que não os inclui ou apresenta uma representação estigmatizada.

Por essas razões profundas relações entre as representações escolares e a formação de identidades individuais e coletivas têm levado educadores a formular projetos educacionais que se contraponham às características que fazem com que a escola reforce desigualdades da atual estrutura social (MOREIRA \& SILVA, 2002, p. 33). Não como um reflexo natural da sociedade, mas de maneira artificial e claramente intencional é que surgem as representações das minorias, com intuito de mudanças sociais - ou de satisfazer as cobranças dos indivíduos que almejam tais mudanças.

Como reflexo destas mudanças de mentalidade, o Ministério da Educação introduziu os pacotes de tecnologias políticas, intitulados de pârametros curriculares nacionais, os PCN, desenvolvidos em um amplo contexto de discussões e produção de saberes. O discurso de base dos parâmetros curriculares brasileiros defende a democratização da escola, e, com isso, aponta significativas reformas no sistema educacional, na escola e na prática docente. Os PCN também exprimem novas visões e representações sobre o mundo e o outro. Estas mudanças no sistema educacional podem contribuir para criar novos olhares da coletividade sobre o diferente, sobretudo ao produzir representações sociais novas, desenvolvendo novos campos epistêmicos em torno do outro e das formas de diferença e diversidade social e cultural.

Alterações de representação social como as propostas pelos PCN influem em percepções e comportamentos, uma vez que esta tem caráter simbólico, significante e construtivo, no sentido de viabilizar a ocorrência dos fatos, de acordo com a maneira como se representam (RANGEL, 2004, p. 62). 
Umas das categorias que por último se inscreveram nestas políticas de representação são os portadores de necessidades especiais. A partir das novas políticas de inclusão, foram criadas também novas necessidades. Tais políticas procuram incluir ao máximo os portadores de necessidades especiais nas escolas regulares, reduzindo ao mínimo o número de freqüentadores das escolas especiais. Tais políticas são válidas especificamente para o ensino público e regular, mas refletem uma mentalidade de época, na qual a inclusão é vista não apenas positiva, como necessária, e, a partir disto, as tentativas de inclusão poderão repercutir nos mais diversos contextos educacionais ou não.

A presença destes indivíduos outrora excluídos dos inúmeros contextos sociais faz com que mudanças aconteçam, muitas vezes, em caráter emergencial. A mais evidente destas modificações é a adaptação do espaço com base em conceitos de acessibilidade, uma vez que, não havendo a facilidade de acesso físico deste indivíduo, torna-se ainda mais difícil a sua inclusão. Porém, a simples mudança no espaço e a inclusão presencial destes sujeitos ainda não contribuem mais efetivamente para que os alunos portadores de necessidades especiais sejam de fatos incluídos dentro do sistema educacional e social.

Mudanças arquitetônicas podem ser feitas em caráter de emergência, mas mudanças de mentalidade requerem muito mais tempo e esforço, pois, enquanto o espaço se modifica de um ano para o outro, as pessoas e suas crenças continuam as mesmas, das quais os sujeitos que outrora eram excluídos do sistema educacional, continuam excluídos. Isto recorrentemente acarreta no fracasso escolar destes para os quais a escola não foi pensada.

Uma primeira evidência desta exclusão deste sujeito como parte do contexto escolar é a falta de representação deste nos livros didáticos. Ao mesmo tempo em que inúmeros grupos sociais, de gênero e étnicos estão lá representados, o portador de necessidades especiais, ao não se ver nestes materiais, não se identifica como um membro pertencente àquele grupo. O uso de imagens em livros didáticos tem passado por uma crescente valorização, como recurso visual para auxiliar o aluno na compreensão dos textos por sua linguagem estar aproximada do contexto do aluno, na construção dos sentidos e na possível veiculação de ideologias e culturas por meio das imagens. Esses fatores podem incidir em diversas áreas, como por exemplo, na formação do professor, que deverá saber também como trabalhar com as mensagens visuais e os designers 
responsáveis pelo projeto gráfico do livro didático, que deverá trabalhar com esses fatores dentro de uma tendência contemporânea de inclusão discursiva dos sujeitos.

Para iniciar uma inclusão efetiva do portador de necessidades especiais no ambiente educacional, e, posteriormente, no mercado de trabalho, é necessário que haja uma mudança também nas representações destes indivíduos nos materiais didáticos, o que já aparece como uma tendência contemporânea que analisaremos a partir deste momento.

Para isso, faremos um estudo de caso com base no material Teens Club, série de 4 livros voltados para o ensino de inglês tendo como o público crianças de 11 a 13 anos, iniciantes no estudo do idioma. A nova versão do livro foi lançada em 2010, enquanto que a versão anterior data do início dos anos 90. No primeiro livro da série somos apresentados a alguns personagens, que estão presentes até o último livro e cujas vidas escolares darão mote para as unidades e lições do livro. Segue abaixo as duas versões das personagens:

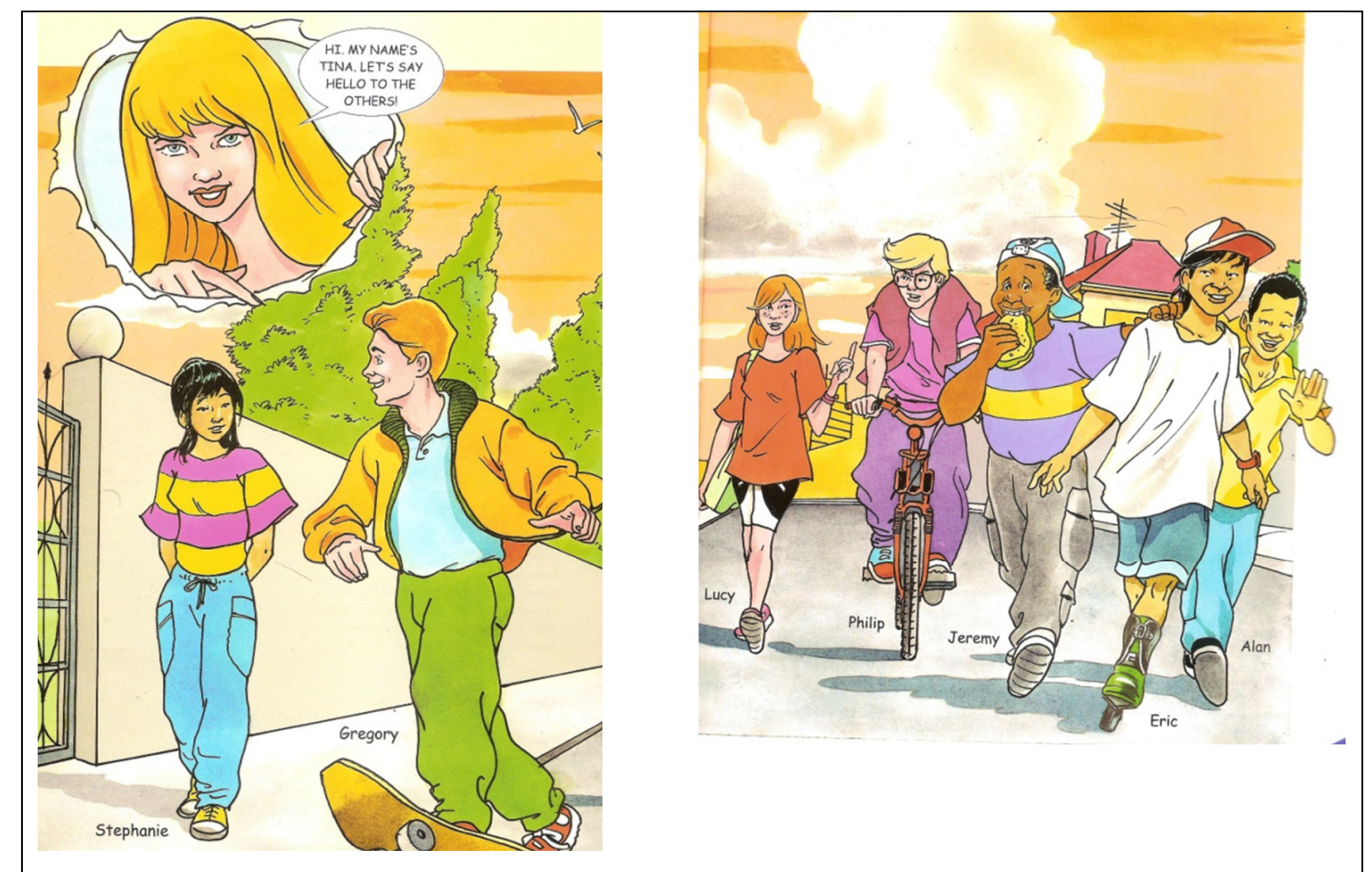

Figura 1: "TEENS CLUB 1" - VERSÃO ANTIGA 


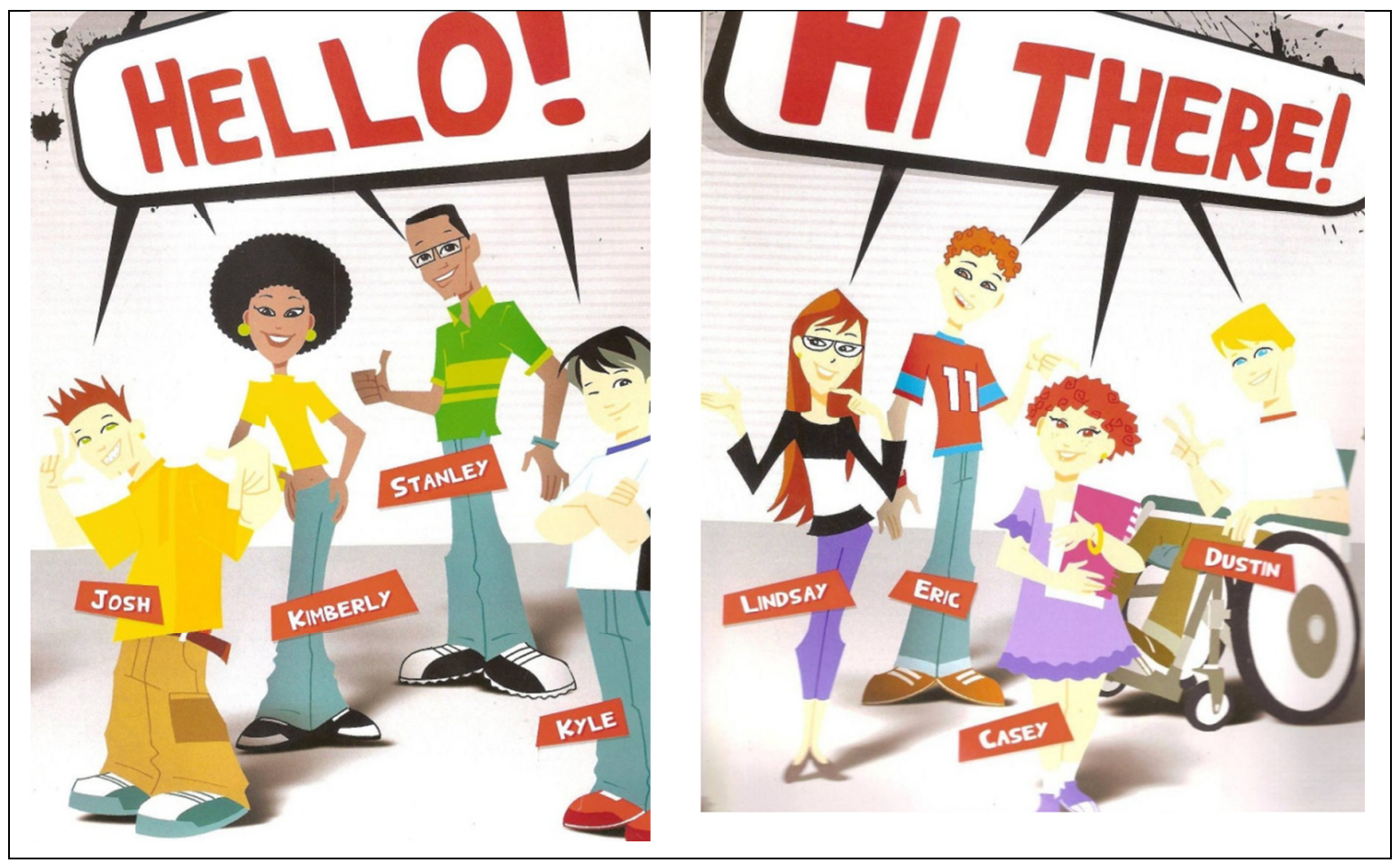

Figura 2: “TEENS CLUB 1" - 2010

Em vários aspectos percebemos uma configuração parecida no grupo, nas duas versões compostas de oito elementos, sendo três meninas e cinco meninos. No entanto, uma das meninas, Kimberly, nesta nova versão aparece representada como negra e um dos meninos, Dustin, é um cadeirante. As duas diferenças marcam uma preocupação com a representação e a inclusão social.

Além disso, nota-se uma modificação nas características gráficas das representações, no primeiro livro, ilustrações feitas à mão, com traços orgânicos e uma linguagem remetendo aos quadrinhos da época. Já na nova versão, apresenta ilustrações vetoriais remetendo ao contexto do mundo digital do jovem atual. Essa mudança de linguagem nas representações visuais, buscando uma aproximação da identidade cultural para quem ela foi produzida - estudantes entre 11 e 13 anos - é uma forma de compreender melhor a mensagem visual expressa no livro.

Diferentemente da maior parte das representações que temos encontrado na mídia, aqui, o cadeirante não aparece nem como uma figura vitimizada, como um "coitadinho", nem como um exemplo de superação, mas como um menino "normal" para sua idade, o que podemos ver nas duas imagens seguintes. 


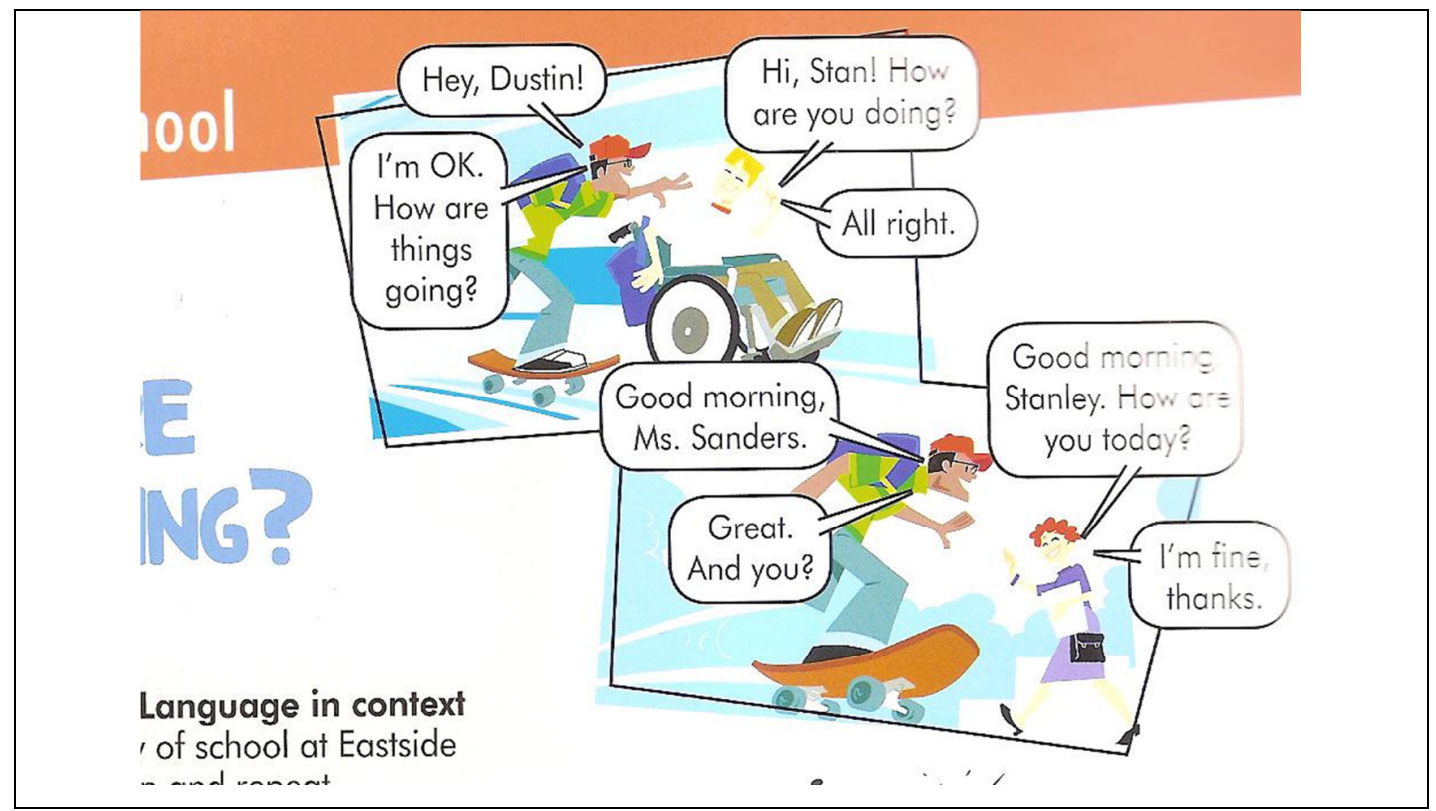

Figura 3

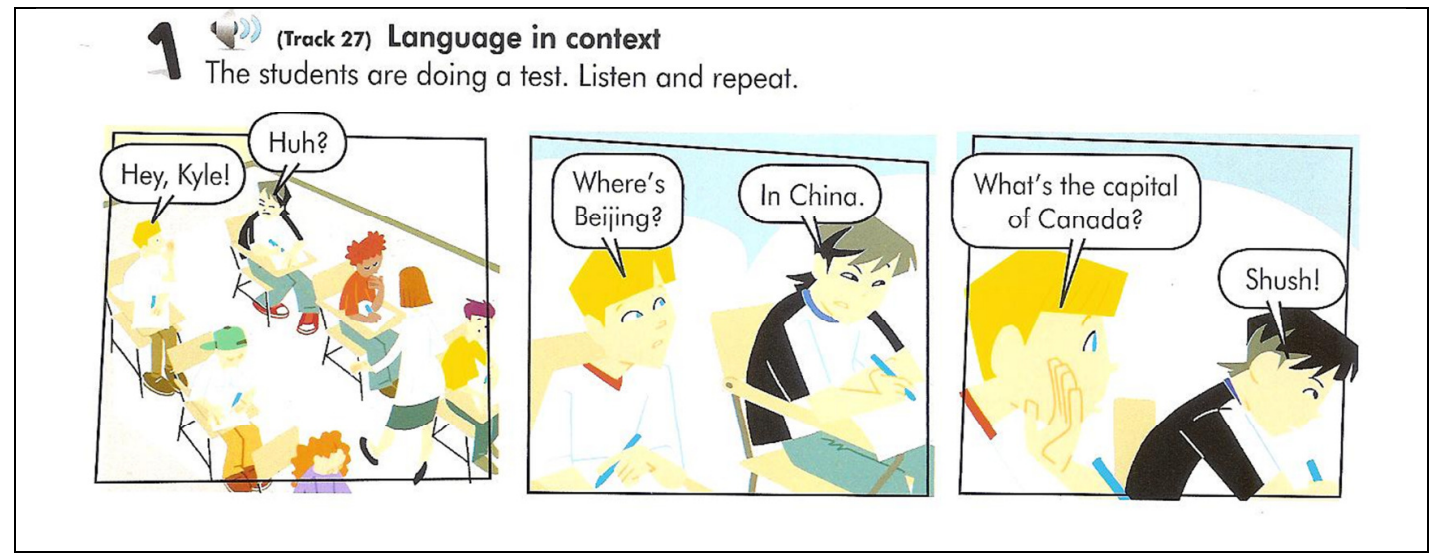

Figura 4

Note-se que na figura 4, temos a personagem de Dustin "colando" em uma prova escolar, o que destaca sua posição de "normalidade" frente ao grupo. Destacamos também o espaço representado na figura 4. Percebemos que se trata de uma sala de aula tradicional, com cadeiras dispostas em longas fileiras, todas voltadas para frente da sala. Dustin senta-se em uma carteira regular como todos os outros alunos. A representação ignora que, em um contexto real, o aluno precisaria de uma carteira adaptada e, se os assentos estivessem seguindo a disposição 
apresentada, Dustin não poderia ficar sentado ao fundo da sala, uma vez que teria problemas de acessibilidade para alcançar o lugar que lhe foi determinado.

Além do mais, Dustin também é representado como um menino autônomo e independente, conforme podemos ver na figura que se segue.

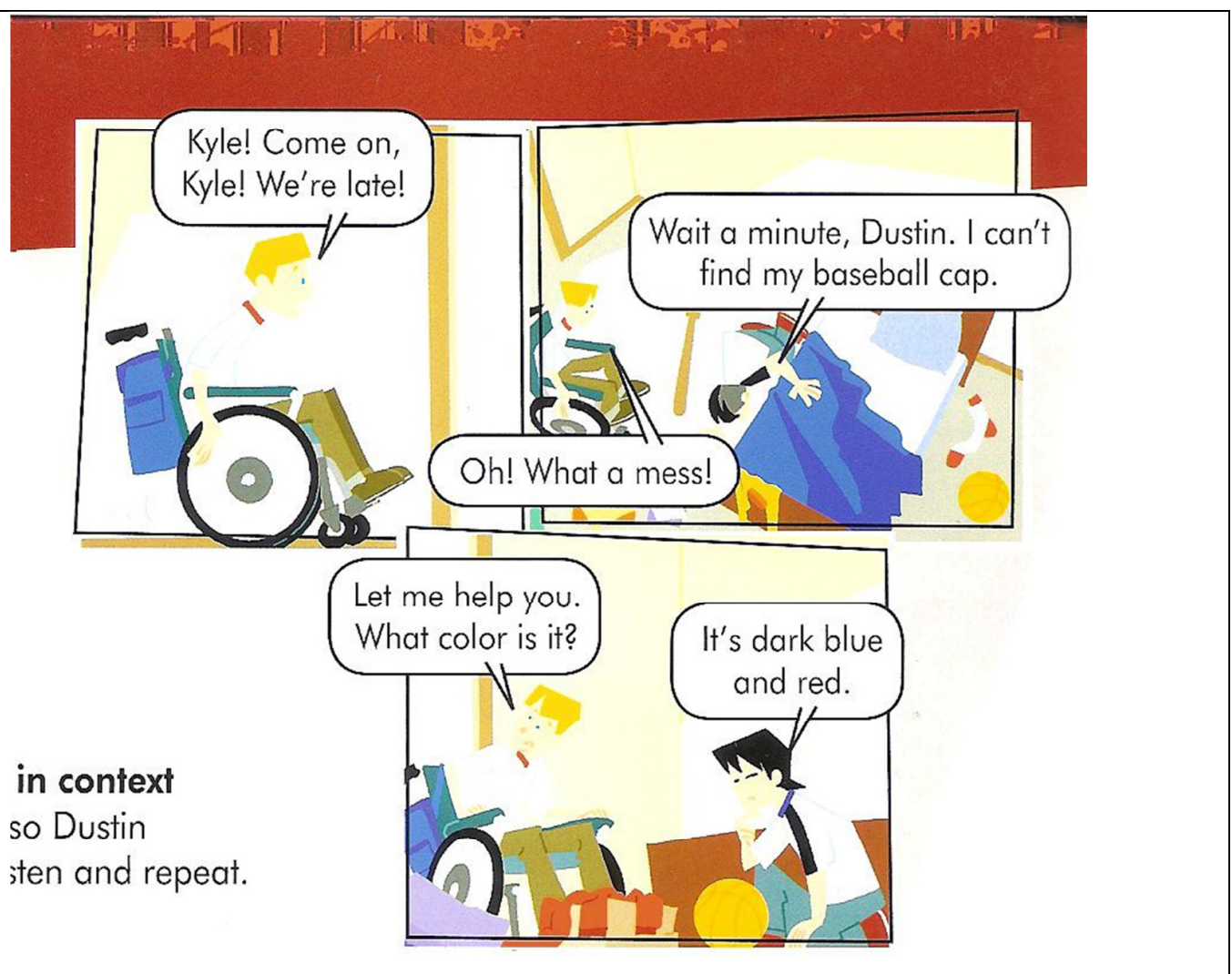

Figura 5

Na figura 5, percebemos Dustin reclamando do atraso e destacando a desorganização do amigo, o que chama a atenção pelo fato de que, mesmo com uma deficiência motora e maiores dificuldades de locomoção, Dustin é capaz de cumprir horários e organizar-se no espaço de maneira eficiente. Além disto, em nenhuma das imagens percebemos o aluno sendo auxiliado fisicamente pelos colegas, o que sugere sua boa adaptação e autonomia, lhe garantindo mobilidade e independência.

Vale chamar a atenção para os momentos em que Dustin não é representado, os contextos dos quais ele é excluído, e com ele a representação de uma identidade de um sujeito portador de 
necessidades especiais. Dustin ainda aparece como único, sem pares em seu contexto. Além disso, em momentos do livro nos quais várias pessoas aleatoriamente são representadas, não encontramos nenhum outro portador de necessidades especiais (ver figura 6).

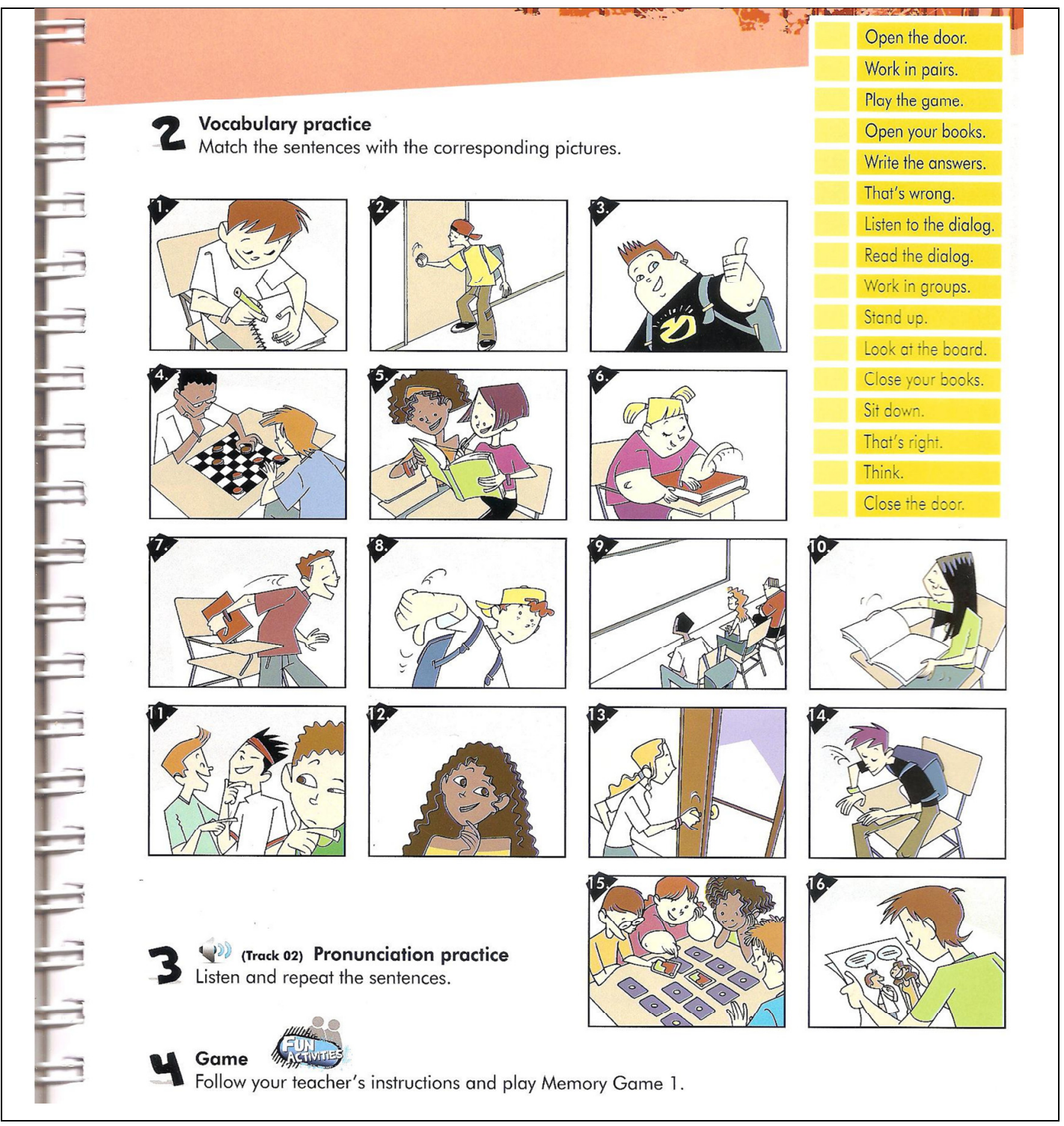

Figura 6

Dustin ainda é completamente excluído da unidade que tem como tema esportes, atividades físicas e materiais esportivos. 
Devemos lembra ainda que o fato de que o enredo da série gira em torno de pequenos romances entre algumas das personagens, assunto do qual Dustin também não faz parte (ver figura 7).

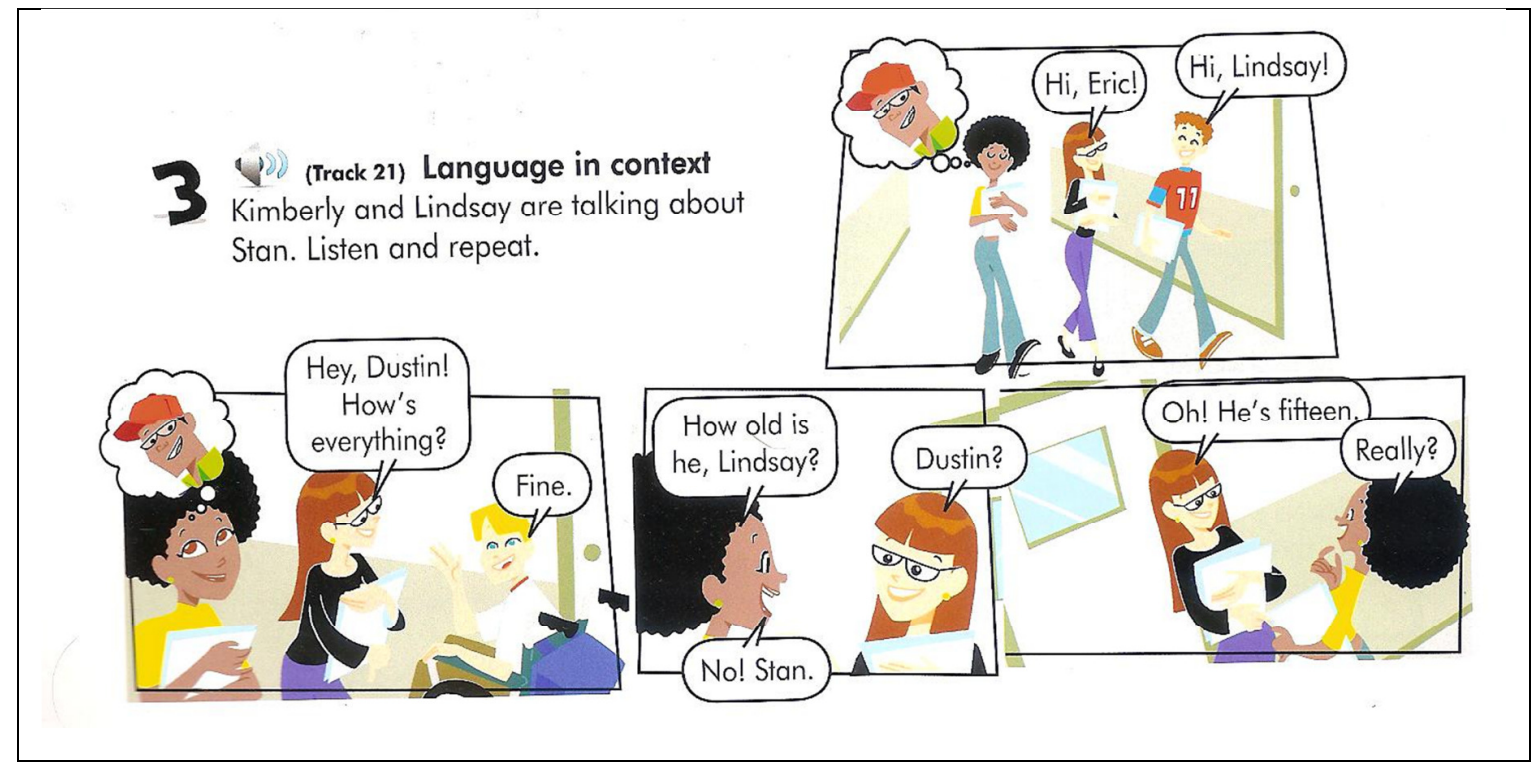

Figura 7

\section{CONCLUSÕES}

A partir das análises dos excertos dos livros didáticos, concluímos que Dustin, o cadeirante, aparece como o único representante de um grupo de pessoas com necessidades especiais. Podemos constatar nos inúmeros livros da mesma editora, que, quando existe a representação deste grupo, ela é sempre feita por meio da imagem de um cadeirante, ou seja, todos os outros portadores de outras necessidades especiais parecem continuar invisíveis para os atores do sistema educacional. Não podemos negar que a simples representação de Dustin já figura como um grande avanço para um sistema educacional que se propõe mais democrático, mas trata-se de um grande avanço especialmente por ser um começo para outras transformações. Ainda há muitas categorias excluídas a serem representadas, e, em algum momento melhor inseridas socialmente.

A representação do portador de necessidades especiais nos materiais analisados é feita exclusivamente de maneira pictórica. A diferença de Dustin jamais ganha voz, jamais se 
transforma em discurso verbal. Não existe nenhuma menção à sua diferença e de suas necessidades, o que parece um sinal de que se evitam temas polêmicos em sala de aula. Percebemos que, a cada vez que a questão da deficiência pode se tornar um tema para debate em sala, como na relação com os esportes e atividades físicas e ainda nos relacionamentos amorosos, a figura de Dustin simplesmente desaparece. Dustin não é representado verbalmente e parecem ser podadas quaisquer oportunidades de que Dustin torne-se um discurso verbal através dos alunos. Evitando dentro do livro didático os problemas que um portador de necessidades especiais encontra nos contextos sociais reais, Dustin mesmo sendo representado, acaba tendo sua diferença anulada.

As políticas de representação dos diversos grupos não têm a intenção de apagar as diferenças e sim de abrir espaço para a convivência e aceitação das diferenças, o que não é o que acontece neste caso. Não podemos ignorar o avanço que constitui que um portador de necessidades especiais esteja representado dentro do livro didático, já que por meio dos olhinhos curiosos dos alunos, aos poucos estas representações vão chegando ao imaginário. Por outro lado, parece haver um esforço contrário para que esta representação da diferença passe o mais despercebido possível aos olhos dos alunos. Um exemplo disso é que, durante o primeiro semestre de trabalho com este novo material, não ouvimos uma única observação dos alunos para o fato de que Dustin usa uma cadeira de rodas. É como se Dustin sempre estivesse estado lá. É preciso representar o "diferente", não para criar uma falsa impressão de que ele é igual, mas de maneira que essas diferenças sejam igualmente respeitadas, porque quanto mais conhecemos a diferença, naturalmente nos damos conta de que, de uma forma ou de outra, o que não existe é o "normal".

\section{REFERÊNCIAS}

CUDER, A. C. Teens' Club, v. 2. São Paulo: CNA, 2000. . New Teens' Club, v. 1. São Paulo: CNA, 2010.

CULLER, J. Teoria Literária: uma introdução. São Paulo: Beca, 1999.

JOLY, M. Introdução à Análise da Imagem. São Paulo: Papirus, 1996. 
KINDEL, E. A. I. A natureza no desenho animado ensinando sobre homem, mulher, raça, etnia e outras coisas mais... (Tese de Doutorado) - UFRGS, Faculdade de Educação, Porto Alegre, 2003.

MOREIRA, A. F. \& SILVA, T. T. Sociologia e Teoria Crítica do Currículo. In:

(orgs.) Currículo, Cultura e Sociedade. São Paulo: Cortez, 2002.

PASSOS, J. S. Identidade e Formação de Profissionais de Letras: a contribuição de Stuart Hall. Revista X, Curitiba, vol.1, p. 34-40, 2008. Disponível em: < http://ojs.c3sl.ufpr.br/ojs2/index.php/revistax/article/view/14015/9483 >.

PASSOS, J. S. Entre Evas e Marias: a representação feminina em Dorotéia. Dissertação (Mestrado em Estudos Literários) - Programa de Pós-graduação em Letras, UFPR, Curitiba, 2009.

MOSCOVICI, A. A representação social da psicanálise. Rio de Janeiro: Zahar, 1978.

RANGEL, M. Pesquisa de representação social como forma de enfrentamento de problemas socioeducacionais. Aparecida: Ideias \& Letras, 2004.

SAID, E. O Orientalismo. São Paulo: Cia das Letras, 2007.

WOODWARD, K. Identidade e diferença: uma introdução teórica e conceitual. In: SILVA, T. T. (Orgs.). Identidade e diferença: a perspectiva dos estudos culturais. Petrópolis: Vozes, 2000.

WORTMANN, M.L.C.; VEIGA-NETO, A. Estudos culturais da ciência e educação. Belo Horizonte: Autêntica, 2001. 